\title{
Un poco más acerca del hermano jesuita Gonzalo Ruiz en Córdoba de la Nueva Andalucía (siglo XVII)
}

\author{
A little more about the Jesuit brother Gonzalo Ruiz \\ in Córdoba de la Nueva Andalucía (XVII century)
}

\author{
Margarita E. GENTILE LAFAILLE \\ Ex Investigador CONICET, \\ Museo de La Plata, \\ y Ex Profesor titular ordinario, \\ Cátedra Instituciones del \\ Período Colonial e Independiente. \\ Universidad Nacional de las Artes, \\ Buenos Aires. \\ margagentile@yahoo.com.ar
}

\begin{abstract}
Resumen: En este breve ensayo retomo y analizo los datos conocidos acerca del hermano jesuita Gonzalo Ruiz con el propósito de investigar su quehacer como pintor de imágenes religiosas en Córdoba de la Nueva Andalucía, a principios del siglo XVII. Asimismo considero la posibilidad de que haya sido, o no, el amanuense y dibujante de la Nueua Coronica atribuída a Guaman Poma.
\end{abstract}

Abstract: In this brief essay I return and analyze the known data about the Jesuit brother Gonzalo Ruiz with the purpose of investigating his work as a painter of religious images in Córdoba de la Nueva Andalucía, at the beginning of the $17^{\text {th }}$ century. I also consider the possibilitiy that he was, or not, the amanuensis and draftsman of the Nueua Coronica attributed to Guaman Poma.

Palabras clave: Gobernación de Tucumán - Jesuitas - siglo XVII - arte colonial - metodología de la investigación- Guaman Poma - Nuеua Coronica.

Keyword: Government of Tucumán - Jesuits - XVII century - Colonial Art - Research methodology - Guaman Poma - Nueua Coronica. 
Sumario:

I. Antecedentes.

II. Datos y comentarios.

III. Bibliografía.

Recibido: septiembre de 2019.

Aceptado: noviembre de 2019. 


\section{ANTECEDENTES}

En algunos de mis trabajos previos hubo un dato periférico, que retomo ahora ${ }^{1}$, común a todos. Hasta tanto se disponga de otras fuentes, su interés radica en lo que aporta tanto a la historia del Arte colonial en la gobernación de Tucumán como a la metodología de la investigación por cómo se llegó a afirmar que el hermano jesuita Gonzalo Ruiz había sido pintor de cuadros religiosos y dejado obra en Córdoba de la Nueva Andalucía a principios del siglo XVII.

$$
* * *
$$

Al fundar Córdoba de la Nueva Andalucía (1573), Jerónimo Luis de Cabrera puso la iglesia matriz bajo la advocación de Nuestra Señora de la Peña de Francia. Años después, Phelipe Guaman Poma de Ayala se refirió varias veces a su devoción por esta advocación mariana; en particular, en los folios 402 y 403 de la Nueua Coronica dibujó bajo el título "Conqvista / Milagro de Santa María" el milagro del Sunturhuasi, portento realizado por Santa María de Peña de Francia.

Las citadas no pasarían de meras coincidencias si no fuese que Luis R. Altamira en su trabajo sobre los pintores coloniales en Córdoba había fechado la estadía del hermano Gonzalo Ruiz en esa ciudad en $1617^{2}$. Años después, el Catálogo publicado por el padre Hugo Storni daba al hermano Ruiz en Córdoba en 1615 como última fecha conocida por este autor ${ }^{3}$. Más adelante, Laura Laurencich decía que Guaman Poma había conocido al hermano Ruiz porque

${ }^{1}$ GENTILE LAFAILLE, M.E., "El Alero de los Jinetes: Iconografía e Historia de sus representaciones rupestres (Cerro Colorado, Córdoba, República Argentina)", (2011) en http://www.rupestreweb.info/alero.html. IDEM, "Un modelo de historia gráfica para armar: "El milagro del Sunturhuasi" (1537-2018)", en La Iglesia y el Mundo Hispánico en tiempos de Santo Tomás de Villanueva (1486-1555), San Lorenzo del Escorial 2018, pp. 805-834; IDEM, "Nuestra Señora de la Peña de Francia en el virreinato del Perú. Notas y comentarios acerca de una advocación mariana políticamente incorrecta (siglos XVI-XXI)", en Bibliographica Americana (Buenos Aires), 14 (2018): 20-42.

${ }^{2}$ ALTAMIRA, L.R., Córdoba. Sus pintores y sus pinturas. Siglo XVI, Córdoba 1951.

${ }^{3}$ STORNI, H., Catálogo de los jesuitas de la Provincia del Paraguay (Cuenca del Plata, 1585 - 1768), Roma 1980. 
éste había sido el dibujante y amanuense de la Nueua Coronica que, además, había sido pergeñada por el jesuita Blas Valera, y no por Guaman Poma como se venía creyendo ${ }^{4}$.

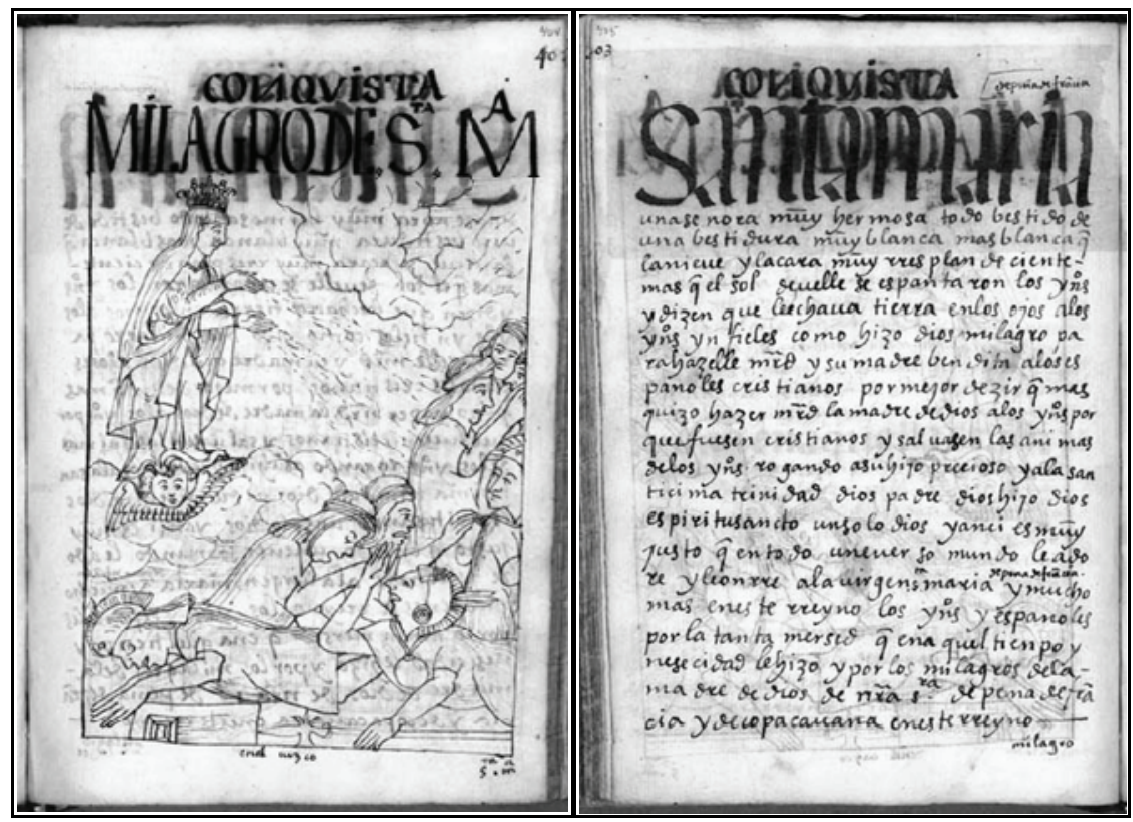

Figura 1. "Conqvista Santa Maria de Peña de Francia", según Guaman Poma c.1613: fs. 402-403. Esta es la única representación de la aparición de María sobre el Sunturhuasi, -edificio incaico en el que los españoles se refugiaron durante el cerco del Cusco, 1536-1537-, en la que ese edificio no figura.

Aquí vale una disgresión: las refutaciones a la autenticidad de los documentos en los que Laurencich respaldó sus afirmaciones, -aunque basadas en fotos y fotocopias-, fueron contundentes ${ }^{5}$; por su parte, la propietaria de dichos documentos

${ }^{4}$ LAURENCICH-MINELLI, L.; MICCINELLI, C., y ANIMATO, C., "Il documento seicentesco $<$ Historia et rudimenta linguae piruanorum $>$ ", en Studi e materiali di Storia delle Religioni (Roma) n.s. XIX (2) (1995) 363-413; LAURENCICH-MINELLI, L.; MICCINELLI, C., y ANIMATO, C., "Lettera di Francisco de Chaves alla Sacra Cesarea Cattolica Maestà: un inedito del sec.XVI", en Studi e materiali di storia delle religioni (Roma) XXII, 1 (1998a) 59-91; LAURENCICHMINELLI, L., "Historia et Rudimenta Linguae Piruanorum ¿un estorbo o un acontecimiento?", en Anthropologica (Lima), 16 (1998b) 349-367; IDEM, "La "culpa del cronista peruano P. Blas Valera", en Anales del Museo de América (Madrid) 7 (1999) 95-109; NUMHAUSER, P., "Documentos Miccinelli: un estado de la cuestión", en Per bocca di altri: Inca, gesuiti e spagnoli del XVII secolo, Bologna 2007, pp. 45-74.

${ }^{5}$ ESTENSSORO, J.C., “¿Historia de un fraude o fraude histórico?”, en Revista de Indias (Sevilla), LVII (210) (1997) 566-578; ADORNO, R., "Criterios de comprobación: el manuscrito 
se negó a que los mismos fuesen estudiados y analizados por investigadores fuera de su propio entorno. Finalmente, el tema entró en un cono de sombra, dejando tras de sí una estela de dudas.

En 2001 supe por Sergio Barraza que una enciclopedia de arte americano daba a Gonzalo Ruiz en Córdoba de la Nueva Andalucía en 1617 donde, además, había pintado un cuadro de san Ignacio de Loyola.

Si bien la presencia de Ruiz en Córdoba estaba fuera de duda, no lo estaba su quehacer como pintor y, por carácter transitivo, la posibilidad de que hubiese sido el amanuense y dibujante de la Nueva Coronica. Veamos qué se sabe de él y las proyecciones de este conocimiento a la historia del arte en la gobernación de Tucumán, entre otros temas.

\section{DATOS Y COMENTARIOS}

Por fuentes jesuitas se sabe que el hermano Gonzalo Ruiz tenía diez y ocho años en 1569, que era mestizo nacido en Chachapoyas ${ }^{6}$, o en Moyobamba ${ }^{7}$, ambos pueblos cercanos, en el norte del virreinato del Perú; en ese momento llevaba siete meses en la orden, sabía leer y escribir, y era "buena lengua", pero según sus superiores "no es para mucho" 8 .

A través de los varios tomos de Monumenta Peruana se pueden seguir sus idas y venidas por Huamanga, Cusco, Chuquiabo, Arequipa, Potosí, Chuquisaca, Huaral, Huacho y Cajatambo; siempre como coadjutor temporal y en su especialidad que era hablar bien en quechua. Aquella primera opinión se matizó con el tiempo destacando su talento para enseñar y predicar a los indios, su perseverancia, oración y humildad". En el "Catálogo..." se lo dio como hermano coadjutor temporal en 1615 en la ciudad de Córdoba ${ }^{10}$.

Miccinelli de Nápoles y las crónicas de la conquista del Perú”, en Anthropologica (Lima), 16 (1998) 369-394; HAMPE MARTÍNEZ, T., "Una polémica versión sobre la conquista del Perú: ¿es auténtica la relación de Francisco de Chávez (1533)", en Escritura y Pensamiento (Lima), 6 (2000a) 33-54; IDEM, "Coloquio Internacional "Guaman Poma de Ayala y Blas Valera: Tradición andina e Historia Colonial (Roma, septiembre de 1999)", en Anuario de la Historia de la Iglesia (España), 9 (2000b) 486-489.

${ }^{6}$ EGAÑA, A., Monumenta Peruana, Roma [1581-1585] 1961, p. 270.

${ }^{7}$ EGAÑA, A., y FERNÁNDEZ, E., Monumenta Peruana, Roma [1602-1604] 1981, p. 253.

${ }^{8}$ EGAÑA, A., Monumenta Peruana, Roma [1565-1575] 1954, p. 284.

${ }^{9}$ En 1601 se le autoriza comulgar una vez más de lo permitido en la semana (Egaña [1601] 1981, p. 573).

${ }^{10}$ STORNI, H., Catálogo de los jesuitas de la Provincia del Paraguay (Cuenca del Plata, 1585 - 1768), Roma 1980, p. 254. 
Ruiz Gonzalo, c.

7. 1615 Córdoba (Arg) [P 7, 3]. quitos, Bolivia) [P 23, 46;

Brabo Inventarios 500];

10. 7.3.1773 Faenza (Ravena,

Figura 2. Ficha de Gonzalo Ruiz según Storni 1980: 254. Desglosada dice: Ruiz Gonzalo, coadjutor, última fecha que le consta a Storni de su existencia: 1615, en Córdoba (Argentina), Paraquaria Cataloguis Breves 7, 3. Aunque figura en esta ficha, el número 3 no está en la lista que Storni dio de documentos revisados en la p.XIX, lo que podría ser un error de imprenta.

Nada se dice de Ruiz como pintor. Sin embargo, Luis R. Altamira afirmaba que Ruiz había aprendido a pintar en Córdoba con el andaluz hermano Bernardo Rodriguez y que el

“... Hermano Gonzalo Ruiz, de quien no se sabe cuándo nació, dónde tuvo lugar su alumbramiento, cuándo ingresó a la Compañia de Jesús, ni dónde dejó de existir. En el "Catálogo 3, de la Provincia del Paraguay" consta que Ruiz hallábase en Córdoba para el año 1617, y dedicaba sus dias a las actividades artísticas. Es muy probable que el Padre Diego de Torres aludiese a él en carta que el 12 de junio de 1615 envió al Padre General Claudio Aquaviva ..."11.

\section{CATALOCO DE LOS JESUTTAS DEL PARAGUAY}

1230/48. Rodríguez Bernardo, $c$.

1. 8.12.1573 Baeza (Jaén, Esp) [P 4/I, 44v];

2. 25.8.1592 Andalucía [ib. 5];

6. 19.9.1604 Lima (Perú) [H 48/I, 208];

4. 29.11.1607 San Salvador de
Jujuy (Arg) [Lozano I, 708 723]; Buenos Aires [HS 48, 18].

Rodríguez Bernardo, c. 1616 forma parte de la expedición del P. Viana [Pastells $1,355]$.

Figura 3. Ficha del hermano coadjutor Bernardo Rodriguez según Storni 1980: 244. Si bien era andaluz, como el citado por Altamira, no figura allí como que haya residido en Córdoba de la Nueva Andalucía.

${ }^{11}$ ALTAMIRA, L.R., Córdoba. Sus pintores y sus pinturas. Siglo XVI, Córdoba 1951, II, p. 27. 
El catálogo citado por Altamira parece ser el mismo citado luego por Storni; no obstante ¿ambos autores obtuvieron del mismo documento datos que podrían ser complementarios?; hasta ahora no hallé respaldo a dicha complementariedad; en cuanto a la referencia a la carta del padre Torres, se trata de una conjetura de Altamira.

Por su parte, el padre Guillermo Furlong decía

"En 1614 no había en Córdoba pintor alguno de algún prestigio, ya que, según informan las Cartas Anuas, queriendo contar con dos cuadros, uno de Nuestra Señora y otro de San Ignacio, uno de los jesuitas, que no pasaba de ser novicio en el arte, (nostrorum studiosus) ejecutó ambos cuadros. El ocultar el nombre de ese pintor, y el no tener una palabra de elogio para esas pinturas, harian creer que valían poca cosa. Años mas tarde, entre 1618 y 1622, actúa como pintor el jesuita Gonzalo Ruiz, que posiblemente sea el anónimo, a que antes nos referimos, pero no conocemos ni las obras que realizó, ni el mérito de las mismas." ${ }^{12}$.

Tampoco este autor dio como seguro que haya sido el hermano Gonzalo Ruiz el pintor anónimo, del que admite, además, no conocer sus obras; fue más allá de las fechas dadas por Altamira y Storni, pero tampoco dijo de dónde obtuvo tales datos.

El siguiente hito bibliográfico es la recopilación de arte y artistas americanos que me señalara Barraza:

"Ruiz, Gonzalo. Pintor jesuita, probablemente español cuyos datos biográficos se ignoran. Consta que en 1617 se encontraba en Córdoba (Argentina) dedicando sus días a sus actividades artísticas. Se sabe que realizó en la ciudad mencionada un cuadro de San Ignacio de Loyola." ${ }^{13}$.

Vicente Gesualdo reunía indiscriminadamente datos sobre algún tema (historia argentina, historia de la fotografía en América, historia de la música en la Argentina, etc.) que luego organizaba a modo de enciclopedia; respecto del hermano Ruiz parece que siguió a Altamira, agregando que podría haber sido español.

12 FURLONG, G., Historia Social y Cultural del Río de la Plata. 1536-1810, Buenos Aires 1969, III, pp. 231-232.

${ }^{13}$ GESUALDO, V., Enciclopedia del Arte en América. Biografias. Buenos Aires 1969, III. 
Ni Storni ni Gesualdo tomaron en cuenta Monumenta Peruana, cuyo primer tomo se publicó en 1954 y en el cual había datos del ingreso a la Companía de Jesús de Gonzalo Ruiz y alguno de sus primeros viajes ${ }^{14}$.

Por su parte, Altamira, Furlong y Gesualdo formaron una línea sucesoria a partir de una afirmación del primero de ellos que daba a Ruiz como pintor, adjudicándole una nacionalidad y cuáles fueron sus obras aun reconociendo que ninguna de ellas había sido ubicada.

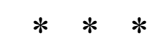

En cuanto a la posibilidad de que Ruiz fuese el amanuense y dibujante de la Nueua Coronica dirigida por Blas Valera, tenemos que aunque éste y Ruiz estaban en Perú en 1569, y ambos provenían de Moyobamba y Chachapoyas ${ }^{15}$, esos datos no dicen más que el haber sido los dos jesuitas, sacerdote uno y hermano coadjutor el otro, originarios de pueblos cercanos.

Ruiz en Córdoba tampoco significa que hubiese formado parte del equipo redactor de la Nueua Coronica que se dispersó tras finalizar el trabajo como afirmaban los documentos publicados por Laurencich; menos aun que aprendiera a pintar y dejase obra en dicha ciudad, como decían los tres autores citados antes $^{16}$.

Busqué obra de Ruiz en Córdoba, sin resultados positivos. Héctor Schenone citó, sin publicar foto de ninguno de ellos, dos cuadros relacionados con el fundador de la Companía: "Universalidad de la doctrina ignaciana", en la residencia, anónimo del siglo XVIII. El otro, "Glorificación de san Ignacio", anónimo cuzqueño del siglo XVII en la sacristía de la iglesia de la Compañía.

En cuanto a si el hermano Ruiz fue, o no, devoto de N.S. de la Peña de Francia quedará en el ámbito de su privacidad.

${ }^{14}$ El padre Storni ingresó al Instituto de Investigaciones Históricas de la Compañía de Jesús (IHSI) c. 1960, y allí trabajó hasta su muerte en 2008. EGAÑA 1954, I, pp. 284, 447.

15 EGAÑA, A., Monumenta Peruana, Roma [1565-1575] 1954, pp. 283-284; EGAÑA, A., Monumenta Peruana, Roma [1581-1585] 1961, p. 270; EGAÑA, A., y FERNÁNDEZ, E., Monumenta Peruana, Roma [1602-1604] 1981, p. 253.

${ }^{16}$ SCHENONE, H.H., Iconografia del Arte Colonial: Los Santos, Buenos Aires 1992, II, pp. 466-467. 


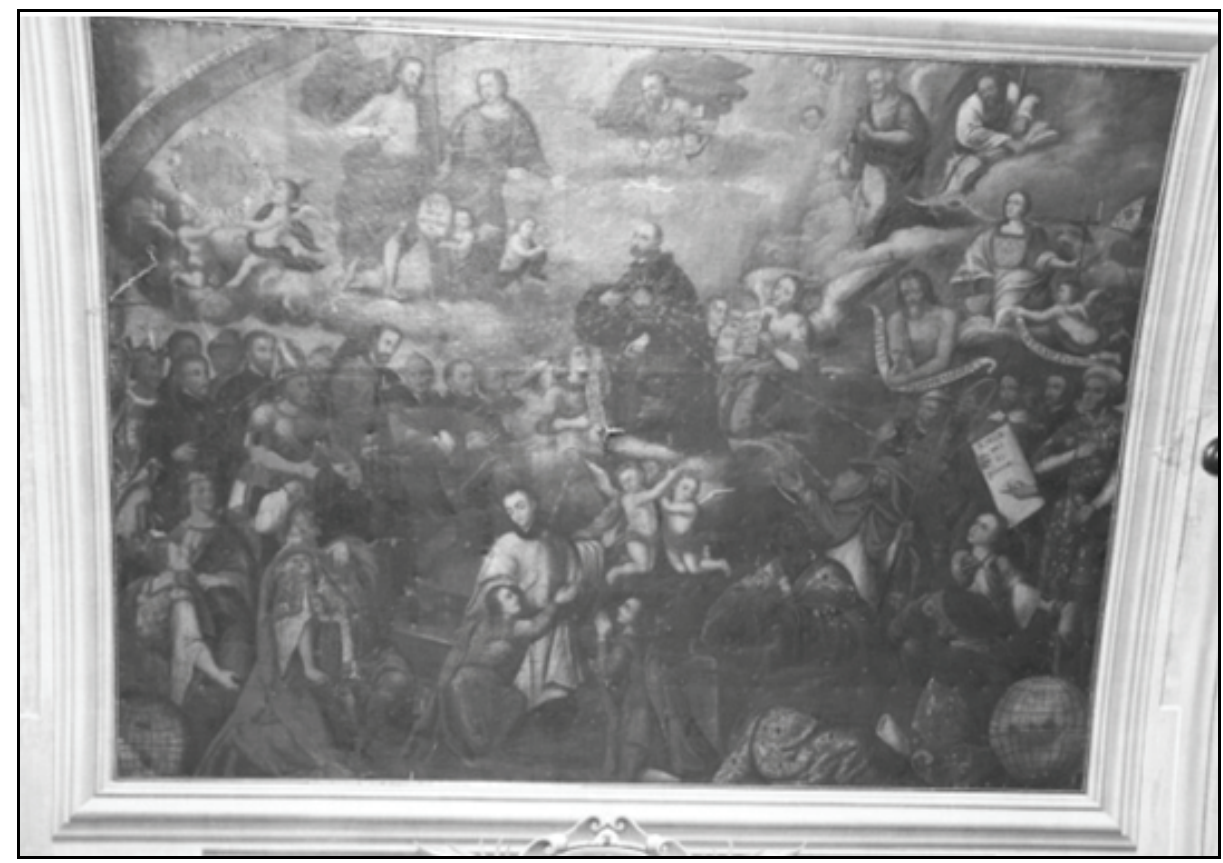

Figura 4. Glorificación de san Ignacio, anónimo cuzqueño del s. XVII. Sacristía de la iglesia de la Compañia, Córdoba. Foto de Hugo A. Pérez Campos, 2006.

Hasta el momento, fuera de las repeticiones de unos a otros autores, no se tienen pruebas de que el hermano Gonzalo Ruiz hubiese sido pintor.

En cuanto a su presencia en Córdoba de la Nueva Andalucía, estaba dentro de las posibilidades que ofrecía la Companía respecto de ubicar en lugares de buen clima a quienes, llegados a cierta edad, ya habían pasado muchos años en continuos trajines apostólicos en territorios inhóspitos, tal como se ve por los viajes de Ruiz. Dado que su especialidad era la enseñanza, catequización y sermones en quechua, Ruiz podría haber continuado cómodamente su apostolado en Córdoba tras la fundación del noviciado en 1608-1609, donde la población quechuahablante fue importante, como dejó ver la actividad de Uzcollo, lenguaraz secular en dicha ciudad ${ }^{17}$.

${ }^{17}$ GENTILE, M.E., "Las preocupaciones de un indio del Perú en Córdoba: el testamento de Baltazar Uzcollo", en Investigaciones y Ensayos (Buenos Aires), 52 (2002) 199-252. 
Y, como si fuese poco, el estilo de los dibujos que graficaron una maloca $^{18}$ en el Alero de los Jinetes, en terrenos de la encomienda de la familia del jesuita Hernando de Torreblanca dirigen la atención a la posibilidad de que él mismo u otro (¿el hermano Rodriguez?) los hubiese realizado o facilitado su realización ${ }^{19}$.

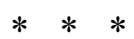

Siguiendo a Altamira, Furlong, Gesualdo y sus epígonos, en mi opinión mas bien parece que hubo en Córdoba de la Nueva Andalucía, entre 1615 y 1622, dos jesuitas con el mismo nombre; uno era español y pintor, en tanto que el otro era mestizo y "buena lengua". Pero en las fuentes jesuitas éditas que conozco solamente quedó registro del hermano coadjutor, mestizo y lenguaraz.

Es de notar asimismo que los autores citados tampoco tomaron en cuenta que las pinturas anónimas podrían haber sido realizadas por el hermano Bernardo Rodríguez, a pesar de que en el Catálogo publicado por Storni tampoco figura su paso por Córdoba ${ }^{20}$.

Llegados a este punto, cabe preguntarse cuál podría haber sido la fuente tan puntual y especializada de la que Altamira obtuvo sus datos; por mi parte, aun no pude ubicarla.

En mi ensayo sobre N.S. de la Peña de Francia expliqué porqué ésta fue una advocación mariana políticamente incorrecta. De ahí que las convergencias que venimos de ver permitan pensar, en otra línea, acerca de la posibilidad de que esta devoción hubiese sido una contraseña entre personas que tuviesen opiniones contrarias al quehacer de los funcionarios españoles: Cabrera contradiciendo las órdenes del virrey Toledo, Guaman Poma como autor de la contestataria Nueua Coronica.

${ }^{18}$ Ataque y saqueo de un pueblo indígena.

${ }^{19}$ GENTILE LAFAILLE, M.E., "El Alero de los Jinetes: Iconografía e Historia de sus representaciones rupestres (Cerro Colorado, Córdoba, República Argentina)”, (2011) en http://www.rupestreweb.info/alero.html.

${ }^{20}$ Dicho Catálogo no es exhaustivo; allí tampoco figuran los viajes de Ruiz. 
Reitero que la afirmación de Altamira no corresponde y excede en mucho a la cita del Catálogo de Storni ${ }^{21}$; en tanto que la autenticidad de los documentos / objetos napolitanos que daban al hermano Ruiz como amanuense y dibujante de la Nueua Coronica no quedó demostrada, de manera que tampoco podemos pensar en su quehacer como pintor.

En otras palabras, hasta ahora no pasan de ser interesantes datos como la devoción de Cabrera y Guaman Poma a N.S. de la Peña de Francia, la fundación del noviciado jesuita, el lenguaraz Uzcollo, el hermano jesuita Gonzalo Ruiz en Córdoba y la maloca pintada en la roca del Alero de los Jinetes; y que todos ellos se localicen en dicha ciudad, en su entorno inmediato y que fuesen coetáneos. Tal vez su articulación con otros datos provenientes de otras fuentes permitan perfilar mejor, o no, lo que éstos sugieren.

\section{BIBLIOGRAFÍA}

- ADORNO, R., "Criterios de comprobación: el manuscrito Miccinelli de Nápoles y las crónicas de la conquista del Perú", en Anthropologica (Lima), 16 (1998) 369-394. http://revistas.pucp.edu.pe

- ALTAMIRA, L.R., Córdoba. Sus pintores y sus pinturas. Siglo XVI, Córdoba 1951.

- EGAÑA, A., Monumenta Peruana, Roma [1565-1575] 1954. https://books. google.com.

- EGAÑA, A., Monumenta Peruana, Roma [1581-1585] 1961. https://books. google.com.

- EGAÑA, A. \& Fernández, E., Monumenta Peruana, Roma [1602-1604] 1981. https://archive.org.

- ESTENSSORO, J.C., “¿Historia de un fraude o fraude histórico?”, en Revista de Indias (Sevilla), LVII (210) (1997) 566-578.

- FURlONG, G., Historia Social y Cultural del Río de la Plata. 1536-1810, Buenos Aires 1969.

- GENTILE, M.E., "Las preocupaciones de un indio del Perú en Córdoba: el testamento de Baltazar Uzcollo", en Investigaciones y Ensayos (Buenos Aires), 52 (2002) 199-252.

${ }^{21}$ Hasta donde pude indagar, en la Biblioteca Mayor de la Universidad Nacional de Córdoba, que reúne lo que se pudo recuperar tras la expulsión y luego el traslado a Buenos Aires, no se encuentra el catálogo citado por Storni. 
- GENTILE LAFAILLE, M.E., "El Alero de los Jinetes: Iconografía e Historia de sus representaciones rupestres (Cerro Colorado, Córdoba, República Argentina)", (2011) en http://www.rupestreweb.info/alero.html.

- GENTILE LAFAILLE, M.E., "Un modelo de historia gráfica para armar: "El milagro del Sunturhuasi" (1537-2018)", en La Iglesia y el Mundo Hispánico en tiempos de Santo Tomás de Villanueva (1486-1555), San Lorenzo del Escorial 2018, pp. 805-834. https://dialnet.unirioja.es/servlet/ articulo? codigo $=6579868$.

- GENTILE, M.E., "Nuestra Señora de la Peña de Francia en el virreinato del Perú. Notas y comentarios acerca de una advocación mariana políticamente incorrecta (siglos XVI-XXI)", en Bibliographica Americana (Buenos Aires) 14 (2018): 20-42. https://www.bn.gov.ar/micrositios/revistas/bibliographica/ bibliographica-americana- 12 .

- GESUALDO, V., Enciclopedia del Arte en América. Biografias. Buenos Aires 1969.

- GUAMAN POMA DE AYALA, P., El primer Nveva Coronica i Bven Gobierno conpvesto por don... c. 2015. http://www.kb.dk/permalink/2006/ poma/titlepage/es/text/

- HAMPE MARTÍNEZ, T., "Una polémica versión sobre la conquista del Perú: ¿es auténtica la relación de Francisco de Chávez? (1533)", en Escritura y Pensamiento (Lima) 6 (2000a) 33-54.

- HAMPE MARTÍNEZ, T., "Coloquio Internacional "Guaman Poma de Ayala y Blas Valera: Tradición andina e Historia Colonial (Roma, septiembre de 1999)", en Anuario de la Historia de la Iglesia (España), 9 (2000b) 486489. https://www.unav.edu.

- LAURENCICH-MINELLI, L.; MICCINELLI, C., y ANIMATO, C., "Il documento seicentesco $<$ Historia et rudimenta linguae piruanorum > ", en Studi e materiali di Storia delle Religioni (Roma), n.s. XIX (2) (1995) 363-413.

- LAURENCICH-MINELLI, L.; MICCINELLI, C., y ANIMATO, C., "Lettera di Francisco de Chaves alla Sacra Cesarea Cattolica Maestà: un inedito del sec.XVI", en Studi e materiali di storia delle religioni (Roma), XXII, 1 (1998a) 59-91.

- LAURENCICH-MINELLI, L., "Historia et Rudimenta Linguae Piruanorum ¿un estorbo o un acontecimiento?”, en Anthropologica (Lima) 16 (1998b): 349-367. 
- LAURENCICH-MINELLI, L., "La "culpa del cronista peruano P. Blas Valera", en Anales del Museo de América (Madrid), 7 (1999) 95-109. https://dialnet.unirioja.es/revista/5576/A/1999.

- NUMHAUSER, P., "Documentos Miccinelli: un estado de la cuestión", en Per bocca di altri: Inca, gesuiti e spagnoli del XVII secolo, Bologna 2007, pp.45-74. http://amsacta.unibo.it/2350/6/Cap1.pdf.

- SCHENONE, H.H., Iconografia del Arte Colonial: Los Santos, Buenos Aires 1992.

- STORNI, H., Catálogo de los jesuitas de la Provincia del Paraguay (Cuenca del Plata, 1585 - 1768), Roma 1980. https://archive.org.

\section{Webgrafía}

- http://www.bmd.bmayor.unc.edu.ar.

- http://bibliotecadigital.aecid.es. 
